Western University

Scholarship@Western

Human Environments Analysis Lab (HEAL)

$3-2020$

Enacting agency: exploring how older adults shape their neighbourhoods

Carrie Hand

Debbie Laliberte Rudman

Suzanne Huot

Rachel Pack

Jason A. Gilliland

Follow this and additional works at: https://ir.lib.uwo.ca/healpub 


\title{
Enacting agency: exploring how older adults shape their neighbourhoods
}

\author{
Carri Hand ${ }^{1,2 *}$, Debbie Laliberte Rudman ${ }^{1,2}$, Suzanne Huot ${ }^{3}$, Rachael Pack ${ }^{4}$ \\ and Jason Gilliland ${ }^{5}$ \\ ${ }^{1}$ School of Occupational Therapy, University of Western Ontario, London, Ontario, Canada, ${ }^{2}$ Graduate \\ Program in Health and Rehabilitation Sciences, University of Western Ontario, London, Ontario, Canada, \\ ${ }^{3}$ Department of Occupational Science and Occupational Therapy, University of British Columbia, Canada, \\ ${ }^{4}$ Department of Women's Studies and Feminist Research, University of Western Ontario, London, Ontario, \\ Canada and ${ }^{5}$ Department of Geography, School of Health Studies, Department of Paediatrics and \\ Department of Epidemiology \& Biostatistics, University of Western Ontario, London, Ontario, Canada \\ ${ }^{*}$ Corresponding author. Email: chand22@uwo.ca
}

(Accepted 9 August 2018; first published online 17 September 2018)

\begin{abstract}
Within research on ageing in neighbourhoods, older adults are often positioned as impacted by neighbourhood features; their impact on neighbourhoods is less often considered. Drawing on a study exploring how person and place transact to shape older adults' social connectedness, inclusion and engagement in neighbourhoods, this paper explores how older adults take action in efforts to create neighbourhoods that meet individual and collective needs and wants. We drew on ethnographic and community-based participatory approaches and employed qualitative and geospatial methods with 14 older adults in two neighbourhoods. Analysis identified three themes that described the ways that older adults enact agency at the neighbourhood level: being present and inviting casual social interaction, helping others and taking community action. The participants appeared to contribute to a collective sense of connectedness and creation of social spaces doing everyday neighbourhood activities and interacting with others. Shared territories in which others were present seemed to support such interactions. Participants also helped others in a variety of ways, often relating to gaps in services and support, becoming neighbourhood-based supports for other seniors. Finally, participants contributed to change at the community level, such as engaging politically, patronising local businesses and making improvements in public places. Study findings suggest the potential benefits of collaborating with older adults to create and maintain liveable neighbourhoods.
\end{abstract}

Keywords: neighbourhoods; person-place interactions; civic engagement

\section{Introduction}

Person and place transact through complex and multi-layered interactions, each continually shaping the other (Cresswell, 2004). The natural, built, social, service and policy features embedded within neighbourhoods can support older adults' participation and wellbeing (e.g. Clarke and Nieuwenhuijsen, 2009; Levasseur et al., 2015). 
At the same time, neighbourhood features can contribute to negative impacts on older adults, such as experiences of marginalisation related to changes in communities (Phillipson, 2007) and social exclusion related to loss of valuable social spaces (Burns et al., 2012). It is less clear, however, how older adults act upon their neighbourhoods. Within a study exploring how person and place transact to shape older adults' social connectedness, inclusion, engagement and participation in occupations, various ways that older adults contribute to and shape aspects of their neighbourhoods emerged as a key mode of transacting with their environments. This paper explores how older adults take action to create neighbourhoods that meet individual and collective needs and wants. Noting the significant conceptual and methodological debates on defining meaningful neighbourhood boundaries (Flowerdew et al., 2008), in this study we adopted each participant's self-defined conception of neighbourhood, an approach consistent with our interest in older adults' perceptions and agency.

Much neighbourhood research focuses on how neighbourhoods support and pose barriers to older adults' participation and wellbeing, positioning them as affected by neighbourhood features but not necessarily as impacting them. However, grounded in frameworks that acknowledge the agency of older adults, emerging research shows that older adults contribute to and influence their neighbourhoods. Such research prompts a shift away from viewing neighbourhoods as static entities that older adults are shaped by, towards viewing neighbourhoods as dynamic and shaped over time by older adults and numerous other factors (Cresswell, 2004). For example, Gardner (2011) found that older adults often initiate interactions with others in their communities, contributing to neighbourhood networks that support community cohesion and individual wellbeing. Ziegler (2012) found that older adults contribute in similar ways to the social life of senior's clubs. In some cases, however, greetings and interactions with neighbours are not reciprocated (Lager et al., 2015). Other contributions made by older adults include emotional and practical support provided to other seniors in their neighbourhoods and advocating within action groups for support and information better suited to their needs (Lager et al., 2013), for community safety (Buffel et al., 2013) and to prevent built environment changes perceived as threats to personal wellbeing and neighbourhood liveability, such as increases in housing density (Vine et al., 2014). Wiles and Jayasinha (2013) have termed activities including volunteering, activism and helping others as 'care for place'. This article builds upon this emerging body of literature to address how older adults enact agency at the level of their neighbourhoods, as well as the contextual characteristics that affect these actions. Understanding these processes can support collaborating with older adults to develop age-friendly practice and policy at the neighbourhood level.

\section{Theoretical framing}

Neighbourhoods as places encompass physical and social elements that have specific meanings to individuals and collectives. This study is grounded in social constructivism (Lincoln et al., 2011), acknowledging the dynamic, multiple and constructed nature of social reality. It is further framed within a transactional perspective of place, which draws upon Dewey ([1929] 1989) to view place as a complex, dynamic web of environmental elements, individuals and groups, that are inseparable from 
one another (Cresswell, 2004; Cutchin, 2004; Andrews et al., 2007). These elements continually interact with and shape each other over time. For example, place can shape individual characteristics such as motivations and values, while individuals are elements of the environment that also exert an influence upon it (Cutchin, 2004). We further attended to engagement in occupations, defined as meaningful sets of activities and roles that individuals and collectives perform in context (Law et al., 1996), as a key way in which environment and person intersect. This study is further informed by the model of ageing well of Wahl et al. (2012), which drew upon the Ecological Theory of Aging (Lawton and Nahemow, 1973). Wahl et al. (2012) proposed that complex person-environment interchanges contribute to the experience of ageing and described two processes of person-environment interchanges. The first is environment-related belonging, which is driven by experiences and related to subjective evaluations of place, such as how spaces become meaningful places, the affective, cognitive and social bonds to a place/ environment, and behaviours over time in the physical environment. The second person-environment process is environment-related agency, which involves goaldirected behaviours related to the environment and an individual's perceived control over the environment. The current study, therefore, explored the transactions between older adults and their neighbourhoods and the ways in which older adults enact environment-related agency.

\section{Methods}

\section{Methodological approach}

This paper is based upon a study exploring how person and place transact to shape older adults' social connectedness, social inclusion and social engagement in neighbourhoods. We implemented an ethnographic methodological approach involving multiple methods (Hand et al., 2017b), enabling exploration of participants' socially and historically situated experiences (Lecompte, 2002), with different methods promoting diverse and deeper understandings (Nunkoosing, 2005; Polkinghorne, 2005; Suzuki et al., 2007; Huot and Laliberte Rudman, 2015). The methods were based upon a scoping review examining combinations of qualitative and geospatial methods for exploring person-place transactions among older adults (Hand et al., 2017a), as well as ethnographic studies conducted by Gardner $(2011,2014)$. The study includes community-based participatory research approaches (Minkler and Wallerstein, 2008) as well; an advisory panel composed of researchers, older adult community members, city planners, providers of senior's programming and other community stakeholders met monthly to implement the study collaboratively. Ethical approval for the study was granted by the Western University Non-Medical Research Ethics Board.

\section{Participants and setting}

The study, which took place in a mid-sized Canadian city, involved 14 participants, including 11 women and three men who ranged in age from 66 to 94 years (see Table 1). All participants were White, most reported they 'had money left over at the end of each month', all reported good, very good or excellent health, 
Table 1. Participant characteristics

\begin{tabular}{|c|c|c|c|c|c|c|c|}
\hline $\begin{array}{l}\text { Participant and } \\
\text { neighbourhood }\end{array}$ & $\begin{array}{l}\text { Age in } \\
\text { years }\end{array}$ & Gender & $\begin{array}{l}\text { Finances at } \\
\text { month's end }\end{array}$ & Marital status & $\begin{array}{l}\text { Self-reported } \\
\text { health status }\end{array}$ & $\begin{array}{l}\text { Ethnic or cultural } \\
\text { background }\end{array}$ & $\begin{array}{l}\text { Years in current } \\
\text { neighbourhood }\end{array}$ \\
\hline $1 \mathrm{~A}$ & 71 & Female & Some money left over & Separated/divorced & Excellent & Ukrainian, British & 4 \\
\hline $3 \mathrm{~B}$ & 80 & Female & Some money left over & Widowed & Excellent & British & 6 \\
\hline $4 B$ & 84 & Male & Some money left over & Married/common-law & Good & English & 60 \\
\hline $7 \mathrm{~A}$ & 73 & Male & Some money left over & Married/common-law & Good & English, Canadian & 43 \\
\hline $8 \mathrm{~A}$ & 84 & Female & Some money left over & Married/common-law & Good & $\begin{array}{l}\text { German, Scottish, } \\
\text { Irish, French }\end{array}$ & 20 \\
\hline $9 \mathrm{~B}$ & 65 & Female & Some money left over & Married/common-law & Very good & British & 12 \\
\hline $13 \mathrm{~B}$ & 76 & Female & Some money left over & Widowed & Very good & English, Dutch & 25 \\
\hline $14 \mathrm{~B}$ & 82 & Female & $\begin{array}{l}\text { Just enough to make } \\
\text { ends meet }\end{array}$ & Separated/divorced & Excellent & Not stated & 35 \\
\hline
\end{tabular}


and good physical mobility, and all had access to a variety of transportation options. Individuals were eligible to participate if they were age 65 years or more, lived in one of two target neighbourhoods for at least one year, could participate in an interview in English, were not working full-time, and were able to go out into their community, independently or with a companion or mobility device. Recruitment occurred through posting notices within the two neighbourhoods at places frequented by older adults, including libraries, senior centres, pharmacies and grocery stores. Census data from a few years prior to the study showed that the median individual income was Can $\$ 30,121$ in Neighbourhood A and was Can $\$ 32,502$ in Neighbourhood B, while the city median individual income was $\$ 29,478$ (City of London, 2018). Neighbourhood A had grid-like streets, was fairly flat with sidewalks on all streets and a long-standing commercial core containing a variety of small, local businesses. This core area was comprised primarily of two blocks of occupied storefronts along one street that was lined with on-street parking on both sides. Neighbourhood B had curving streets and contained an ageing regional shopping centre in its core and had other dispersed stores and services. The shopping centre had lost its primary retail anchors over the past 15 years; government and other services had moved into several retail spaces while a number of spaces remained unoccupied. The terrain of this neighbourhood is fairly flat, with sidewalks or partial sidewalks on more major streets but not on smaller ones.

\section{Data collection}

Three different methods of data collection were used with each participant. One method was a narrative interview in which participants were asked to tell their stories of being in their neighbourhoods, at present and across time, following Wengraf's (2001) open narrative elicitation process and guidelines provided by Reissman (2007). Following the use of open-ended narrative prompts, questions were integrated in the narrative elicitation related to social connectedness and inclusion, and isolation and exclusion, in their neighbourhoods, daily occupations and social interactions. A second method involved spatial-temporal activity monitoring and included global positioning system (GPS) tracking, an activity/travel diary (Shoval et al., 2010) and a follow-up interview. Participants carried a small GPS device for four days and completed a diary logging where they went, what they did and with whom they interacted. GPS data were converted into maps. Participants then engaged in a semi-structured interview involving the maps and their diaries, during which they described experiences of social connectedness, inclusion and engagement in the places they visited, and the activities they performed in them. The third method comprised 'go-along interviews', in which a researcher accompanied participants to a local destination of their choosing (Kusenbach, 2003; Carpiano, 2009; Gardner, 2011). Along the way, the researcher engaged the participant in an informal interview and conducted participant observation, attending to the physical and social environment, social interactions and occupations in which the person engaged.

Almost all data collection sessions were completed by one researcher (RP), lasted 30-120 minutes, took place at a location of the participant's choice and considered the participant's self-defined neighbourhood. Data collection sessions 
were audio-recorded and transcribed verbatim. The researcher immediately recorded reflexive notes following each data collection session. The researchers (RP and principal investigator $\mathrm{CH}$ ) also met regularly to discuss ongoing data collection and analysis, and discussed findings with the broader research team and advisory panel, engaging in a process of collective reflexivity to optimise data collection and analysis (Tracy, 2010).

\section{Data analysis}

Interview data provided details about the nature of contributions by participants and how they viewed themselves and their neighbourhoods; activity diaries and map data illustrated time spent in neighbourhood places, and interactions within them; and observations during go-along interviews revealed much about the social behaviours of participants. Within the analysis process, coded data from each method was brought into dialogue with data from other methods. Aligned with the broader study purpose, initial analysis focused on how person and place transact to shape older adults' social connectedness, inclusion and engagement in neighbourhoods. This analysis began with close reading of interview transcripts, activity/ travel diaries, observation and reflexive notes, and viewing maps. We used narrative analysis techniques (Lieblich et al., 1998) to identify idea units, emerging themes and key storylines within the interview text, diary and map data. In attending specifically to the narrative data, we paid close attention to and coded ways participants constructed particular types of identities and how they integrated stories to convey and support such identities (Reissman, 2007). We used map visualisation (MacEachren, 1994) to identify spatial practices, patterns and themes (Loebach and Gilliland, 2016), and reviewed quantitative map data such as time spent walking to identify patterns and themes further. We integrated data across and within sources to enhance the integrity of the findings both through comparison of codes, but also examining points of convergence and divergence in how participants constructed themselves, their neighbourhoods and their activities across data types. We also looked for opportunities to explain or illustrate the findings of one method through another (Bryman, 2006). A key thematic area that emerged from the initial analysis was the ways in which older adults influence and contribute to their neighbourhoods. We focused further analysis on this area, repeating previous analysis steps in an iterative process. Looking within and across participant data, we identified a variety of ways older adults contribute to their neighbourhoods and looked for negative cases. Codes were then grouped through inter-linked ideas to form themes. Throughout analysis we engaged in reflexive note writing and discussion.

\section{Findings}

We present three intersecting themes that highlight the diverse ways that older adults played a role in shaping their neighbourhoods including: being present and inviting casual social interaction, helping others and taking community action. Within each theme, actions taken by participants and the contextual conditions that shape these actions are discussed, highlighting the ways in which person and environment transact. Participants are mentioned according to number and 
neighbourhood (A or B). Within direct quotes, an ellipsis (...) indicates omission of some of the participant's statement for conciseness and a dash (-) indicates a pause in speaking.

\section{Being present and inviting casual social interaction}

This first theme addresses how older adults engaged in everyday actions in somewhat routine, taken-for-granted ways that appeared to contribute to both a personal sense of belonging in the neighbourhood and a collective sense of connectedness. In relation to the idea of 'being present', many participants talked about the time they spend in their neighbourhoods, outside their homes, engaging in occupations such as walking, attending organised activities then staying for casual chatting, or visiting cafés and other local establishments. Being present seemed to come from a desire for social interaction, and in turn contributed to the social context of neighbourhood places through creating social spaces in neighbourhoods and contributing to the collective. The diary, map and interview data showed that most participants were regularly present in their neighbourhoods and interview data revealed the ways in which they were present and contributed to a sense of being known and knowing others. Participant 4 B stated, 'We don't hang around in one another's houses but we all know one another. You all wave to people as they go by' and Participant 11 A stated, 'It doesn't matter where we go just to see people, even if it's a wave and a nod but you recognise that somebody.' This participant further elaborated, explaining:

Even just that - we said, 'Hello,' to a bunch of people we didn't know. I saw three people I did know ... That's very, very important to both of us ... My husband and I, we've been here over ten years now and we just say we cannot get over how much that means to us. That we can almost just go anywhere and see some people we know, just in passing. That's really important to us. (Participant $11 \mathrm{~A}$ )

In these exchanges, 'friendly recognition' (Kusenbach, 2003: 476) was occurring, which is a welcoming way of greeting people that 'demonstrates personal recollection and kindness towards other locals', such as saying the person's name and smiling. Participants were observed behaving in this way many times in Neighbourhood A, and less frequently in Neighbourhood B. Neighbourhood A's core commercial area created opportunities for interactions with shop-keepers and other customers; in addition, the nearby river and attendant wildlife provided topics for conversation in which most residents could engage. These neighbourhood features, along with the fact that nearly every neighbourhood street had a useable sidewalk, seemed to draw the participants out of their homes and into chance interactions with others. Participants described making an effort to get to know the local business community, a process that seemed to build a collective sense of belonging, and seemed to be helped along by friendly business owners and staff:

It's quite friendly. It's absolutely wonderful. We even go into most of the stores in [the core area] as most of the people who lived here long enough, where they know us by first name, we know them by first name. And you go in and you say, 
you know, hi, [name], et cetera, or whatever, and then at the [specific] store, [the owner is] there, and his mom and dad. And [his] mother founded that store there. In fact, we were there the opening day, so I always tease her. (Participant 7 A)

You go to the [local restaurant] and you know the waitresses there, so that gives you a feeling of belonging, you know ... it makes you feel as though you're part of the neighbourhood. (Participant $4 \mathrm{~B}$ )

Participants from Neighbourhood A and, to a lesser extent, Neighbourhood B, appeared to feel a strong sense of environment-related belonging (Wahl et al., 2012) as well as place attachment, that is, one's bond with place, including personal meanings attached to place and emotional ties to place (Rubinstein and Parmelee, 1992). While Neighbourhood B had similar stores, services, restaurants and cafés to Neighbourhood A, the shops were more dispersed; in addition, sidewalks were not present on all streets in Neighbourhood B. These conditions seemed to limit opportunities for interactions with other people. One exception was the central shopping centre in Neighbourhood B, where some participants interacted with others in a food court, at exercise classes and in an indoor walking group.

While simply 'being present' often resulted in social interaction, participants also used different methods to invite and foster social contact more directly, further building social spaces. We saw participants greeting people and pets, 'And these are my doggies! How are you? Hello!' (Participant 3 B), and saying hello to everyone, 'I don't take chances, but I usually just meet everybody head-on and look them in the eye and kind of smile or say hello' (Participant 11 A). Participants seemed to build upon chance meetings with strangers, to engage in longer interactions. One participant stated:

As a matter of fact, I go out of my way to do it sometimes. If I see a person like in the mall, I go there. And I saw a person on a wheelchair. He's got a medal there, I say to him, 'Oh, you were in the Middle East. I see you got the Africa star.' He said, 'Yeah.' So I talked to him. I have no problem talking to people. (Participant $10 \mathrm{~B}$ )

In some cases, strategies to engage socially extended to modifying the physical environment to create physical places that invited social contact. A participant related:

They're [large bushes] blocking the porch. I don't want to hide, I don't want to sit up there and watch people. I want to be in view, I want people to know that, you know, I can - I can see them and to say hello. So I had them ripped out and I planted all kinds of beautiful flowers. (Participant $1 \mathrm{~A}$ )

At the same time, participants spoke of the need to gauge their efforts of inviting contact, ensuring that they were not being overbearing and were respecting others' social styles, demonstrating the thought process behind such actions.

And so I've been outside shovelling snow and so on and they're out there but they've never said anything. I didn't want to, I don't want to, I don't want to push it. So probably when the weather is nice because they do sit out on the porch a lot and 
I do as well. So probably one day what I'll do is just wave to them and then stroll over. Just do it on in a casual basis, not force myself. (Participant $1 \mathrm{~A}$ )

Both being present and inviting and engaging in casual interactions seemed to attach meaning to certain locations; these locations then became valuable places to visit, showing the ways in which environment-related agency and environment-related belonging transact. An exchange between the interviewer and Participant $8 \mathrm{~A}$ illustrates how a particular physical place had become a social space in which one could anticipate achieving a sense of connection and belonging:

Interviewer: The people that you had coffee with, was this sort of prearranged? Like, you were planning to meet them, or you just happened to run in to them?

Participant: No, I just knew that they would be there...

Interviewer: And it was just a happy coincidence that there were people there that you could have coffee with?

Participant: No. There's always somebody there. There's always somebody in the coffee shop there. So.

It was also clear that being present in neighbourhood places created opportunities for valued exchanges and developing relationships, particularly in Neighbourhood A. Friendly recognition became a foundation for forming such relationships (Kusenbach, 2003). A participant discussed her activity/travel diary and stated:

I met a lady in the park walking her dog. We walked together up the ravine to the [coffee shop], where I left her and continued on. I don't say what we talked about, but we had, we had quite a conversation, that lady and I ... I have since met her a couple times at the - she goes to the [coffee shop] quite often. So now we stop and talk when I do see her. (Participant $8 \mathrm{~A}$ )

Some participants built long-standing relationships with neighbours through being present and inviting contact. For example, one participant stated:

you can share a lot of life just in the driveway or the fence or knocking on the door, if you need to go say what you need to say or borrow something that you're missing for your recipe. You know or take them something or you know Christina [pseudonym], my Greek neighbour, she's brought us lots of treats of things over the years and yeah so those two families are the main ones. (Participant $2 \mathrm{~A}$ )

In other cases, friendly recognition and casual interactions did not lead to anything deeper, in part because 'it's really over time that you build this rapport' (Participant 2 A).

Analysis of the observations made during go-along interviews as well as the verbal data from all interviews demonstrated that participants in Neighbourhood A interacted within three types of relationships identified by Gardner (2011), including relationships related to proximity, such as neighbours, related to service, such as 
store and waiting staff, and related to chance, such as interactions with strangers. In contrast, as noted on the go-along interviews, participants in Neighbourhood B rarely interacted with strangers by chance, except occasionally within the shopping centre, while they did report interacting with neighbours and service providers. These neighbourhood social interactions occurred in 'third places', described by Oldenburg (1989) as informal, inclusive gathering places that are neither work nor home, such as shopping centres and coffee shops. Other interactions occurred in transitory zones (Gardner, 2011) such as sidewalks, lobbies and queues in stores. Vine et al. (2014) highlighted the importance of shared common territories and similarity between residents in supporting social interaction. Likewise, in Neighbourhood A the core area of shops and services and surrounding streets formed a common territory, and similarities among participants and other community members were observed, including similar activities (walking, enjoying coffee at a café) and similar neighbourly interaction style, that seemed to promote sense of belonging and in turn a desire to contribute to collective belonging through environment-related agency.

In some cases, agency was enacted in ways that involved setting boundaries and avoiding social contact. There were some specific areas that participants chose not to be present in, for example an 'unfriendly' bakery, a busy and noisy coffee shop, or a park in Neighbourhood A. One participant stated:

Even when there's nobody there, I don't usually go through there because a lot of times they've left garbage and stuff there. That's true ... I just don't feel the need to - no, actually I wouldn't worry about my personal safety. It's just a choice. I don't need to see two or three guys sitting there drinking beer and wetting themselves or whatever they're doing. I don't need to see that particularly. (Participant $11 \mathrm{~A})$

This participant drew a distinction between people in her community who are welcomed and those who are not. Another participant chose to be present in the same park, in the company of possibly the same men, and was almost assertively present. She did not see a danger for herself despite the worries of others, and navigated these messages and went about the neighbourhood as she likes:

[My husband] worries about me walking by the river ... 'don't be wandering around by the river'. I don't, like, I don't worry about things like that. I've never had anybody - I've never had any troubles so I ... So I don't worry. So I do what I want to do ... they're sitting there drinking beer on those steps, and they offered to lift my cart up for me. I mean, I haven't had anybody be rude to me. (Participant $8 \mathrm{~A}$ )

The different perspectives and behaviours of these two participants highlight the potential for older adults to shape neighbourhoods through being present or not being present, and potentially act to include or exclude others.

Being present in one's neighbourhood, inviting casual social contact and being open to social contact all appeared to contribute to the social character of a neighbourhood. Analysis suggested that the interactions were dependent, in part, on the 
physical and social features of neighbourhood places, having a shared territory and seeing the same people regularly. Older adults appeared to experience environment-related belonging and place attachment, and in turn purposefully engaged in meaningful neighbourhood-based social interactions and relationships, demonstrating environment-related agency to contribute to the social fabric of the community. These actions seemed to further create a sense of environment-related belonging, in a transactional and cyclical process.

\section{Helping others}

The second important means through which older adults enacted agency and contributed to community building was through helping others, such as checking on neighbours, driving friends to appointments, service work through churches and sharing their expertise. Consistent with a transactional perspective, context, particularly perceived gaps in supports and resources, seemed to prompt the act of helping and shaped the ways in which participants provided assistance. Several participants provided practical and emotional support to friends and neighbours, filling what they saw as gaps in community services and supports. In some cases, support was extended to younger community members who were seen as facing mental health barriers. One participant described how she steps in to fill a gap she sees in mental health services in her area:

We didn't see, for instance, someone begging in the parking lot at the grocery store. Sometimes I see that now. And I've often thought if [a local community mental health service] was still here, that wouldn't happen because that person would be [receiving services] and they wouldn't be doing that ... They'd be learning different skills ... and another one who has an anxiety disorder, I hire them once in a while to do things for me because he's able-bodied. And get him to do things that [my husband] can't do. So I hire him. He's on a disability pension. (Participant $8 \mathrm{~A}$ )

Consistent with other studies that have found that older adults contributed to their communities through giving social and functional support to other older adults (Lager et al., 2013), some participants helped other seniors, especially those who do not have children or family nearby. One participant stated that she helps a neighbour, by taking her to medical appointments, organising her medication, helping her get groceries and driving her to church:

I do have one widow friend from way back then who is very needy and she's in a lot of problems right now ... I'm her lifeline to tell you the truth. (Participant 12 B)

Participants also described helping friends and neighbours transition to more supportive housing. For example, one participant took a friend to visit a retirement home, and is considering that as an option for herself:

I said, you know, you live in [the retirement home] and I can still pick you up and take you to bridge and take you to [our social club], because we, you know, go to a lot of the same - we have a lot of the same friends and that - and she relies on me to drive her and so on. (Participant $3 \mathrm{~B}$ ) 
Participants expressed a sense of the inevitability of moving to a retirement or nursing home, for their neighbours and for themselves, and these sentiments seemed to underpin the suggestions and help that participants provided.

There comes a time when you can't manage on your own. If you can't drive to the grocery store and, um, she wouldn't be able to continue to live here in her condo, which she loves, and she's a very social person. (Participant 3 B)

If you can walk around the house that's fine and you can get one of my [sic] children to do the grocery shopping for you, you could still live here, but if it's impossible to walk around the house and then I guess you haven't got any option, you have to go to a nursing home. (Participant $4 \mathrm{~B}$ )

Just as participants enacted agency to bound their social interactions, participants sometimes set boundaries on how, when and to whom they offered help. They expressed difficulty setting boundaries once a helping relationship developed:

And the care co-ordinator keeps telling me [that] you have to keep saying how much you can do, but the thing is how can I limit myself if there's no one else to pick up the slack. I don't know. (Participant 12 B)

As a result, some participants described setting initial boundaries to avoid developing those relationships. For example, Participant $14 \mathrm{~B}$ stated she ended a friendship because the other person was looking for too much emotional support, and she is now careful in her choice of friends. There seemed to be a limit to what some participants were willing and/or capable of doing.

I'm very helpful and very willing to help but as the decline continues, I mean it's great when you're 75 and let's go for a walk around the block, I don't really want to go by myself. [Then it's], 'wait till I get my walker, can you stop and help me try on some clothes?' That's the evolution that you're looking at with helping seniors. And I'm not a caretaker. I can be a friend but I can't be a caretaker. (Participant 9 B)

In addition to limiting specific roles, participants exerted control through limiting their relationships and interactions with others who might become needy.

Yeah, lots of neighbours I've never seen or don't know. And in some respects it's intentional because of my early experience with the people, because most of them are older than me, even now. Lots of them are older than me and I don't really want to get involved, because you end up getting asked to make beds and cook meals and 'my kids are coming, can you put the turkey in the oven?' Oh, sure I can put it in the oven but then she tells me she wants it stuffed first (laughs). (Participant 9 B)

Similar to the previous theme, in which 'being present' in neighbourhoods could act to include or exclude others, placing these boundaries regarding helping can act to exclude some older adults from community life. 
Viewing participant maps in the context of their interview and diary data showed that much of the support that participants provided to others involved driving friends and neighbours to locations outside the immediate neighbourhood. Often, these resources and services were not located in the immediate neighbourhood, prompting a need for transportation to places such as bridge clubs, churches and shops.

Overall, participants' data suggested that older adults enact environment-related agency by helping others in a variety of ways, often relating to characteristics of the neighbourhood or wider environment, such as gaps in social and health services, lack of family support or absence of other neighbourhood resources. The participants often set boundaries on the types of support and extent of support they provided, such as limiting contact with older neighbours, withdrawing support or assisting friends to seek additional supports. As participants acted as neighbourhood-based supports for others in their communities, they demonstrated the dynamism of neighbourhoods and a way in which individuals can become elements of neighbourhoods, that is, how person and place co-constitute one another.

\section{Taking community action}

The third theme involved visible actions at a community level, such as engaging politically, patronising local businesses to promote their sustainability and making improvements to public places. Participants demonstrated environment-related agency in ways that intertwined with environment-related belonging; both were shaped by the contextual features of the neighbourhoods. Several participants in Neighbourhood A spoke about attending meetings and advocating against specific types of development to preserve village ambience, such as limiting building height and maintaining the existing architectural style in new buildings. For example, Participant 5 A remarked, 'I don't have any faith in City Hall at all when it comes to planning.' Further, participants in both neighbourhoods appeared to value neighbourhood resources, potentially motivating them to advocate to protect such resources, similar to a previous study that showed that older residents sought to defend valued social, psychological and economic elements of their neighbourhood (Vine et al., 2014). The residents of Neighbourhood A and this area's history of successful neighbourhood-level change could have further encouraged their community advocacy.

Participants also described patronising local businesses, as 'businesses come and go and wanting certain businesses to stay and so that's why I [patronise them]' (Participant $2 \mathrm{~A}$ ). Participant $6 \mathrm{~A}$ did all of her spending over the four days of activity tracking in her neighbourhood, and emphasised the importance of having a local grocery store. This was also emphasised by Participant $5 \mathrm{~A}$, who described the local grocery store as 'an anchor and it brings people into the village and then they do other things, like I do, I go from place to place on a day'. Further, Participant 11 A reported doing 'guerilla gardening' to improve a local public garden, and others have cleaned up graffiti or sent pictures of graffiti to city officials to have them clean it, which 'seems to work' (Participant $11 \mathrm{~A}$ ). Similar to community advocacy, these actions seemed rooted in attachment to place and environment-related belonging. 
Participants also described, however, the ways in which this form of agency sometimes met barriers or did not achieve the planned or desired community action or change. Participant $9 \mathrm{~B}$ was on her condominium's board of directors, and stated she did not feel the processes were fair and ethical. Voicing her concerns did not seem to accomplish anything, so she resigned from the board, effectively removing herself from the situation. In addition, in many cases advocating against neighbourhood development was not effective, and several Neighbourhood A participants spoke about increased traffic volume and related issues. In Neighbourhood $\mathrm{B}$, participants expressed disappointment and anger about the decline of a oncevibrant shopping centre, with one stating:

That [mall] was great because you could often shop there and the clothing and whatever. So I'm disappointed with what's happened to that [mall], really disappointed, and it's only getting worse because the people that own it now seem to be more interested in renting to medical, and that's good 'cause that serves the neighbourhood. But now they've put in a government, a huge big government area for Service Canada, so we've lost all that area for stores as well ... they took away the bookstore and the library and post office and services like that. (Participant $13 \mathrm{~B}$ )

The activities within this theme appear linked to protection of the neighbourhood, similar to Fritz and Cutchin (2017), who described how older adults defended an area with many vacant and run-down homes, through maintaining vacant properties to deter crime, and communicating with local government and media to raise awareness of and address issues. As participants in the current study enacted agency at the community level, they appeared to draw on a sense of environment-related belonging in an iterative process.

\section{Discussion}

The study findings suggest that an important way that older adults transact with their neighbourhoods is through exerting an influence on and shaping the neighbourhood. They enact environment-related agency in diverse ways, through being present and inviting casual social interaction, helping others and taking community action. The study also revealed instances in which older adults cannot take action and may feel powerless. The participants actively and intentionally worked to construct the neighbourhood over time through everyday interactions as well as involvement in collective actions, similar to Lager et al. (2013) who found that older adults can play active roles within processes of urban change.

Previous studies have noted the contributions that older adults make to the social aspects of neighbourhoods (e.g. Gardner, 2011), and civic contributions such as joining community groups and volunteering (e.g. Lager et al., 2013). Building upon this literature, the current study highlights additional contributions, including the ways in which older adults help friends and neighbours in informal ways, expanding notions of civic engagement, which is often considered to mean formal volunteering (Martinson and Minkler, 2006). Older adults have been viewed as a resource that can be accessed, to fill the gaps in government services and the social safety net, by providing service to others through volunteering. Accordingly, 
the participants in the current study appeared to view themselves as resources that could fill needs. At the same time, these findings show the potential for seniors involved in helping others to become overwhelmed and the precarity of this type of support.

Regarding contributions to the social fabric of a community, the current study identified actions of older adults across a wider scale than in previous studies. Gardner (2011) and Vine et al. (2014) noted the social contributions that older adults made to their communities, and Lager et al. (2013) reported on the contributions that older adults make to locales such as senior centres, while also noting that interactions seemed to be limited to exchanges with other older adults in places dominated by older adults. Ziegler (2012) further found that older participants contributed to the social life of senior's clubs, and engaged in casual social interactions there, but that they were not able to achieve similar interactions and levels of sociability in their neighbourhoods, for reasons such as barriers created by car travel and increased social distance. A shared territory and similarity among individuals can support interactions among community members (Vine et al., 2014), and this appeared to be the case among participants living in Neighbourhood A. The shared territory of the core service and shopping area and the collective attachment to place (Degnen, 2016) that appeared present within the neighbourhood and the study participants seemed to support casual social interactions and create a sense of community. These interactions may also help to create the conditions through which older adults connect with and ultimately provide assistance to others in need of support. The interactions may further contribute to interdependence among community members and taking community action.

Key contributions of this paper are the ways in which we situate agency and richly describe the ways in which older adults agentically interact with their neighbourhoods. Bandura (2006: 164) conceptualised agency as to influence intentionally one's functioning and life circumstances' and further posited that human agency is in dynamic interplay with social systems. Wahl et al. (2012) built upon Bandura's work to describe the process of environment-related agency, which involves older adults reacting to their environments as well as taking proactive action to create and sustain environments to meet their needs. The findings of the current study contextually situate agency at various scales, including at the level of individuals and collectives, within microsettings such as the few nearest streets, and towards the larger neighbourhood. The study findings also illustrate environment-related agency over time, with development of relationships, fluctuations in provision of support and reactions to neighbourhood change. While environment-related agency is expected to decline with age, with older adults exerting less and less influence over their environments over time (Wahl et al., 2012), this study raises questions about this expectation. In particular, this study's focus on participation in occupations highlighted the degree of engagement with the environment, by providing examples of what participants were actually doing within the various places. The participants in the current study continued to influence their environments in older age and study findings suggest that agency can also be enacted by bounding social contact and setting limits. Seamon (1979) and later Kusenbach (2003) have discussed withdrawal and engagement with elements of the environment and the findings of the current study add nuance to these concepts. Many participants engaged at various scales and performed 
all three types of action that we identified, while others engaged only in certain activities. The participants involved in helping other seniors seemed to have great awareness of the needs of others and the lack of resources in their neighbourhoods, and in some cases were heavily engaged socially and instrumentally, and in other cases limited their support. There were also instances within all three types of action in which participants disengaged from the environment, due to dissatisfaction with an element of the environment, inability to change the situation or a wish to exert control and set boundaries. Thus, as older adults make contributions to their neighbourhoods, they may engage to a greater or lesser extent with different environmental elements. The findings also illustrate some ways in which older people work in concert towards common goals, in particular the themes of being present and inviting casual social interaction and taking community action, and support Bandura's (2006) concept of collective agency, in which people work together to achieve an outcome.

The model of Wahl et al. (2012) also includes the relational concept of personenvironment resources that can support agency. Thus, in Neighbourhood A, contributing to neighbourhood sociability and taking community action were more prominent, potentially due to the available person-environment resources to support such action. In addition, findings also show how environment-related belonging, especially in Neighbourhood A, transacts with environment-related agency, each influencing the other. Thus, the study findings provide further insight into the transactional nature of person and place, and illustrate the prominent role that engaging in occupations, in this case acting upon the neighbourhood, plays within this transaction, adding to emerging research regarding person-place transactions in later life (e.g. Fritz and Cutchin, 2017).

\section{Limitations}

Despite using a variety of recruitment strategies in venues selected to reach diverse participants, the study sample does not reflect the diversity within the neighbourhoods. In addition, the selected neighbourhoods do not represent the diversity of the city's neighbourhoods. Greater diversity in the sample may have led to additional findings about contributions to community and conditions that may support and prevent these contributions. As well, the study findings are bounded in that the perspectives of older adults were privileged; future studies incorporating perspectives of other neighbourhood members could expand understandings of the implications of older adults' agency.

\section{Implications}

The findings of this study suggest a number of neighbourhood-level actions that could help to capitalise on the contributions that older adults make to their communities and could help to maintain and support social connectedness, participation in occupations and wellbeing among older adults. Details about the contributions that older adults make to their local communities could be disseminated widely, providing information that challenges dominant discourses regarding ageing. In addition, older adults, municipalities, private business and providers of activity programmes could all work to create spaces that support casual social interactions. Such spaces would 
involve a shared territory and some similarity among people who use them and could be a valuable setting in which older adults and other community members contribute to creating a vibrant neighbourhood social life.

The social and practical assistance that participants provided to other older adults and their limits in doing so highlight gaps in support for older adults. These gaps could relate to limited availability and accessibility of health and social services, and limited neighbourhood resources, e.g. local medical services, grocery stores, and housing options that can support ageing in place. Findings regarding the informal care-giving that older adults provide can also be shared with organisations that provide health and social services to seniors, potentially to inform care-for-the-caregiver services, such as support in setting appropriate boundaries and information about local services and supports. Such a network of informationsharing and connecting to services could be useful in reaching older adults who need services but have difficulty accessing them.

Methodologically, the use of multiple methods within this study enabled the diverse ways that older adults contributed to their neighbourhoods to be captured. Future research could explore the contributions that older adults make in neighbourhoods with characteristics different from those in the current study, such as neighbourhoods with lower household incomes or with fewer local resources, to generate findings that could be transferable to a wider variety of settings. The concept of agency in relation to neighbourhoods can be explored further, including the scale in which it occurs, the diversity of activities, change in agency over time and in relation to context, and setting limits as a form of agency.

\section{Conclusion}

This study identified ways in which older adults exert agency to shape their neighbourhoods, including being present and inviting casual social interaction, helping others and taking community action, as well as limits of older adults' ability to influence their neighbourhoods. The study illustrated how environment-related agency and belonging shape each other, how neighbourhood features and other contextual elements support and bound such agency, and how forms of agency develop and change over time. The findings further illustrate the transactional and dynamic nature of person-place relationships at various scales. Study findings suggest the potential benefits of collaborating with older adults to create and maintain liveable neighbourhoods.

Acknowledgements. We would like to thank the 14 study participants who generously provided their time to participate in the study.

Author contributions. $\mathrm{CH}$ conceptualised and designed the study, analysed and interpreted the data and drafted the manuscript. DLR, SH and JG contributed to study design and data interpretation, and RP contributed to data analysis and interpretation. All authors reviewed and commented upon the manuscript.

Financial support. This work was supported by the Social Science and Humanities Research Council of Canada (application number 430-2015-00618).

Conflict of interest. The authors declare no conflicts of interest.

Ethical standards. Ethical approval for the study was granted by the Western University Non-Medical Research Ethics Board. 


\section{References}

Andrews GJ, Evans J and Wiles JL (2007) Re-spacing and re-placing gerontology: relationality and affect. Ageing and Society 33, 1339-1373.

Bandura A (2006) Toward a psychology of human agency. Perspectives on Psychological Science 1, 164-180.

Bryman A (2006) Integrating quantitative and qualitative research: how is it done? Qualitative Research 6, 97-113.

Buffel T, Phillipson C and Scharf T (2013) Experiences of neighbourhood exclusion and inclusion among older people living in deprived inner-city areas in Belgium and England. Ageing \& Society 33, 89-109.

Burns VF, Lavoie J-P and Rose D (2012) Revisiting the role of neighbourhood change in social exclusion and inclusion of older people. Journal of Aging Research 2012, 1148287.

Carpiano RM (2009) Come take a walk with me: the 'Go-Along' interview as a novel method for studying the implications of place for health and well-being. Health \& Place 15, 263-272.

City of London (2018) Neighbourhood Profiles. Available at www.london.ca/About-London/communitystatistics/neighbourhood-profiles/Pages/default.aspx.

Clarke P and Nieuwenhuijsen ER (2009) Environments for healthy ageing: a critical review. Maturitas 64, $14-19$.

Cresswell T (2004) Place: A Short Introduction. Malden, MA: Blackwell.

Cutchin MP (2004) Using Deweyan philosophy to rename and reframe adaptation-to-environment. American Journal of Occupational Therapy 58, 303-312.

Degnen C (2016) Socialising place attachment: place, social memory and embodied affordances. Ageing \& Society 36, 1645-1667.

Dewey J ([1929] 1989) Experience and Nature, 2nd Edn. LaSalle, IL: Open Court.

Flowerdew R, Manley DJ and Sabel CE (2008) Neighbourhood effects on health: does it matter where you draw the boundaries? Social Science \& Medicine 66, 1241-1255.

Fritz H and Cutchin MP (2017) Changing neighborhoods and occupations: experiences of older African-Americans in Detroit. Journal of Occupational Science 24, 2, 1-12.

Gardner PJ (2011) Natural neighborhood networks: important social networks in the lives of older adults aging in place. Journal of Aging Studies 25, 263-271.

Gardner P (2014) The role of social engagement and identity in community mobility among older adults aging in place. Disability \& Rehabilitation 36, 1249-1257.

Hand C, Huot S, Laliberte Rudman D and Wijekoon S (2017a) Qualitative-geospatial methods of exploring person-place transactions in aging adults: a scoping review. The Gerontologist 57, e47-e61.

Hand C, Laliberte Rudman D, Huot S, Gilliland J and Pack R (2017b) Toward understanding personplace transactions in neighborhoods: a qualitative-participatory geospatial approach. The Gerontologist 58, 89-100.

Huot S and Laliberte Rudman D (2015) Extending beyond qualitative interviewing to illuminate the tacit nature of everyday occupation: occupational mapping and participatory occupation methods. OTJR: Occupation, Participation and Health 35, 142-150.

Kusenbach M (2003) Street phenomenology: the go-along as ethnographic research tool. Ethnography 4, 455-485.

Lager D, Van Hoven B and Huigen PPP (2013) Dealing with change in old age: negotiating working-class belonging in a neighbourhood in the process of urban renewal in the Netherlands. Geoforum 50, 54-61.

Lager D, Van Hoven B and Huigen PPP (2015) Understanding older adults' social capital in place: obstacles to and opportunities for social contacts in the neighbourhood. Geoforum 59, 87-97.

Law M, Cooper B, Strong S, Stewart D, Rigby P and Letts L (1996) The person-environment-occupation model: a transactive approach to occupational performance. Canadian Journal of Occupational Therapy 63, 9-23.

Lawton MP and Nahemow L (1973) Ecology and the aging process. In Eisdorfer C and Lawton MP (eds), The Psychology of Adult Development and Aging. Washington, DC: American Psychological Association, pp. $464-488$.

Lecompte M (2002) The transformation of ethnographic practice: past and current challenges. Qualitative Research 2, 283-299. 
Levasseur M, Généreux M, Bruneau J-F, Vanasse A, Chabot E, Beaulac C and Bédard M-M (2015) Importance of proximity to resources, social support, transportation and neighborhood security for mobility and social participation in older adults: results from a scoping study. BMC Public Health 15, 503.

Lieblich A, Tuval-Mashiach R and Zilber T (eds) (1998) Narrative Research: Reading, Analysis, and Interpretation, Vol. 47. Thousand Oaks, CA: Sage.

Lincoln Y, Lynham S, Guba E (2011) Paradigmatic controversies, contradictions, and emerging confluences, revisited. In Denzin N and Lincoln Y (eds), The Sage Handbook of Qualitative Research, 4th Edn. Thousand Oaks, CA: Sage, pp. 97-128.

Loebach J and Gilliland J (2016) Neighbourhood play on the endangered list: examining patterns in children's local activity and mobility using GPS monitoring and qualitative GIS. Children's Geographies 14, 573-589.

MacEachren AM (1994) Visualization in modern cartography: setting the agenda. In MacEachren AM (ed.), Visualization in Modern Cartography. Tarrytown, NY: Elsevier Science, pp. 1-13

Martinson $\mathbf{M}$ and Minkler M (2006) Civic engagement and older adults: a critical perspective. The Gerontologist 46, 318-324.

Minkler M and Wallerstein N (eds) (2008) Community-based Participatory Research for Health: From Process to Outcomes, 2nd Edn. San Francisco, CA: Jossey-Bass.

Nunkoosing K (2005) The problems with interviews. Qualitative Health Research 15, 698-706.

Phillipson C (2007) The 'elected' and the 'excluded': sociological perspectives on the experience of place and community in old age. Ageing \& Society 27, 321-342.

Oldenburg R (1989) The Great Good Place: Cafe's, Coffee Shops, Bookstores, Bars, Hair Salons and Other Hangouts at the Heart of a Community. New York, NY: Marlowe and Company.

Polkinghorne DE (2005) Language and meaning: data collection in qualitative research. Journal of Counseling Psychology 52, 137-145.

Reissman CK (2007) Narrative Methods for the Human Sciences. Los Angeles, CA: Sage.

Rubinstein RI and Parmelee PA (1992) Attachment to place and the representation of the life course by the elderly. In Altman I and Low SM (eds), Place Attachment. Human Behavior and Environment. Boston, MA: Springer, pp. 139-163.

Seamon D (1979) A Geography of the Lifeworld. New York, NY: St Martin's Press.

Shoval N, Auslander G, Cohen-Shalom K, Isaacson M, Landau R and Heinik J (2010) What can we learn about the mobility of the elderly in the GPS era? Journal of Transport Geography 18, 603-612.

Suzuki LA, Ahluwalia MK, Arora AK and Mattis JS (2007) The pond you fish in determines the fish you catch: exploring strategies for qualitative data collection. The Counseling Psychologist 35, 295-327.

Tracy SJ (2010) Qualitative quality: eight 'big-tent' criteria for excellent qualitative research. Qualitative Inquiry 16, 837-851.

Vine D, Buys L and Aird R (2014) Conceptions of 'community' among older adults living in high-density urban areas: an Australian case study. Australasian Journal on Ageing 33, E1-E6.

Wahl H-W, Iwarsson S and Oswald F (2012) Aging well and the environment: toward an integrative model and a research agenda for the future. The Gerontologist 52, 306-313.

Wengraf T (2001) Qualitative Research Interviewing: Biographic Narrative and Semi-structured Methods. Thousand Oaks, CA: Sage.

Wiles JL and Jayasinha R (2013) Care for place: the contributions older people make to their communities. Journal of Aging Studies 27, 93-101.

Ziegler F (2012) 'You have to engage with life, or life will go away': an intersectional life course analysis of older women's social participation in a disadvantaged urban area. Geoforum 43, 1296-1305.

Cite this article: Hand C, Laliberte Rudman D, Huot S, Pack R, Gilliland J (2020). Enacting agency: exploring how older adults shape their neighbourhoods. Ageing \& Society 40, 565-583. https://doi.org/10.1017/ S0144686X18001150 